\title{
Cyber-Fundraising and North Carolina Public Libraries
}

\author{
by Timothy C. Hunter
}

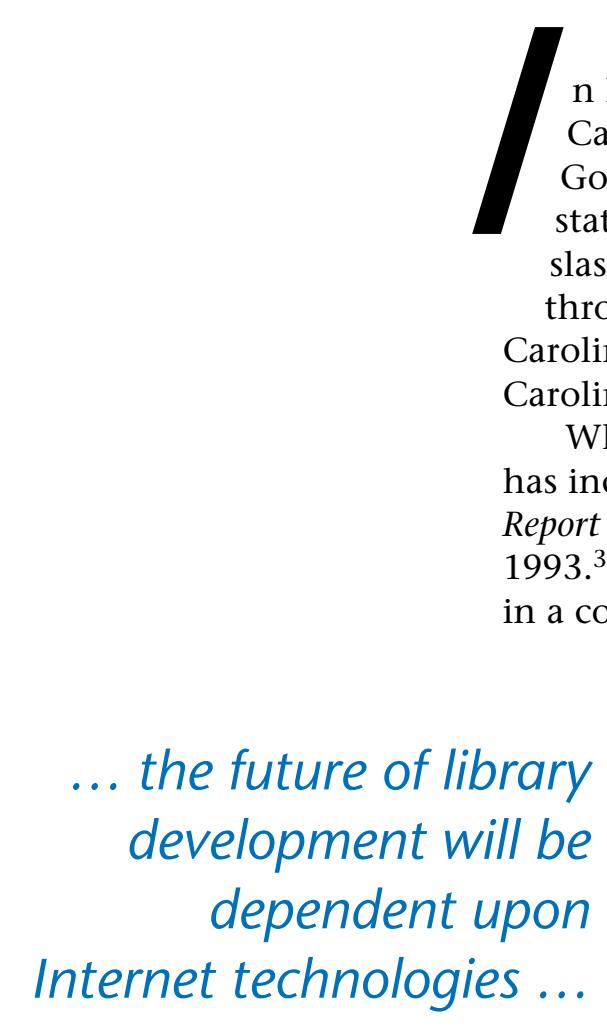

n February 2002, Governor Michael F. Easley announced that North Carolina was suffering from a $\$ 900$ million budget deficit. The Governor's solution to this problem was to withhold \$209 million in state payments to local governments, which in turn forced many to slash local budgets. ${ }^{1}$ Because public libraries are heavily subsidized through these revenues, budget cuts loomed ominously over North Carolina public libraries and their leaders. Libraries in western North arolina were faced with losing as much as 50 percent of their funding. ${ }^{2}$

While librarians are generally a thrifty lot, the state's budgetary crisis has increased the need for effective fundraising. The Library Journal Budget Report for 1999 found that fundraising in libraries has grown 228\% since 1993. ${ }^{3}$ This increased use of fundraising has also intensified competition a complex endeavor. In order to navigate this process, many librarians have turned to the Internet to submit proposals, to research funding sources, and to communicate with colleagues on fundraising issues.

Still, the Internet's communication abilities have remained virtually untapped by library fundraisers. The Internet offers a new medium for communicating with people and, from a fundraiser's point of view, with potential supporters. Some of the Internet's communication methods, such as e-mail, Web sites and listservs, offer library development officers innovative ways to enhance any fundraising program. Adam CorsonFinnerty suggests that the future of library development will be dependent upon Internet technologies that we use everyday and implies that libraries have yet to tap the full potential of these tools for fundraising. ${ }^{4}$ Assuming this is true, North Carolina public libraries need to expand their online fundraising capabilities to compete more effectively for funds in an ever-tightening economy.

\section{What cyber-fundraising is and is not}

According to Dr. Swapan Garain, a senior fellow at Johns Hopkins University, cyber-fundraising "is a technique for the 21 st century." ${ }^{5}$ The Internet's global reach, interactivity, and communal nature provide what many regard as a "potential method for reducing dependency on other traditional methods which are expensive, time-consuming and narrowly focused." 6 
What cyber-fundraising is not, however, is more important than what it is. Cyber-fundraising will not solve all of a fundraiser's problems. Used effectively, it can be a very valuable step toward a new level of fundraising. Used ineffectively, it can lead to trouble.

The Internet will never replace traditional methods of raising funds; however, it can enhance these methods. Corson-Finnerty and Blanchard suggest that if your library does not already have a fundraising program, Web fundraising is not the place to begin. ${ }^{7}$ Thus, cyber-fundraising is best construed as the use of Internet tools to enhance but not completely replace traditional methods of fundraising.

... cyber-fundraising is best construed as the use of Internet tools to enhance but not completely replace traditional methods of fundraising.

\section{Why use online fundraising?}

Online fundraising can bring a new and diverse generation into the fold of library sponsorship. While many of our larger donors may be from the older generation, the Internet has introduced a new "socially engaged Internet user" into the fundraising mix. ${ }^{8}$ According to the Mellman Marketing Group, the next generations of donors are online. The number of Americans with Internet access who report giving money to organizations and social causes represents $25 \%$ of the adult population. ${ }^{9}$ Also, while traditional givers tend to be older and ideologically liberal, the online universe opens an untapped funding source of much greater diversity. Eight-five percent of these socially engaged Internet users are under the age of 60 and ideologically are evenly divided between Democrats (39\%) and Republicans (41\%). ${ }^{10}$

For six reasons, libraries are in a position to engage these new online library donors:

- libraries are accurately perceived as "belonging to everybody"

- libraries provide an easy link to any part of a community via the Internet

- libraries provide some of the best opportunities for lasting memorials

- libraries are perceived as safe, warm, service-oriented pioneers

- libraries in the digital age have become electronic pioneers

- libraries provide a significant return for the investment. ${ }^{11}$

\section{Cyber-fundraising in North Carolina Public Libraries}

I looked at how public libraries are using the Internet for fundraising in North Carolina and found that most are using the Internet to research and apply for grants. Very few libraries are using the Internet beyond its informational purpose.

I surveyed 70 North Carolina Public Library Directors from the North Carolina Directory of Public Libraries. ${ }^{12}$ I sent an email to each director requesting his or her participation in an Internet survey, which could be accessed at http://faculty.catawba.edu/tchunter/survey/index.html. At the end of one month I had gathered a sample of 31 libraries across the state, a $44 \%$ response rate.

Eighty-seven percent of the directors, who responded to the survey. did not currently use the Internet to raise funds. Of those who did not use the Internet, several reasons were identified as obstacles to that use. The belief that online fundraising is ineffective was the foremost objection, while a lack of staff was ranked as the second obstacle. Thirty percent also believed that they lacked the technical expertise to implement such a program. In addition, several other concerns were expressed, including security issues and lack of governmental support and Internet fundraising knowledge. Interestingly, no one said that they lacked the technical infrastructure or time to support such activities.

While many of the directors seemed to be attracted to the idea of 
fundraising on the Internet, they approached the concept with a "cautious optimism." One library director stated that "real live personal contact is more effective," while another affirmed that the "human contact is lost" in Internet transactions. It appears that an underlying skepticism seems to be rooted in concerns over the loss of face-to-face interactions with supporters.

An examination of several North Carolina library home pages confirms that other public libraries are beginning to recognize this same "intrinsic value":

\section{Public Library of Charlotte and Mecklenburg County (PLCMC) http://www.plcmc.lib.nc.us}

PLCMC is one of the state's largest public library systems. PLCMC's home page includes three areas of cyber-fundraising. First, on the home page, is a link entitled "Support your Library-Buy Books Online." This link leads to a page, which advertises a collaborative agreement with Amazon. By entering the Amazon pages through this gateway, Amazon will donate a certain percentage of each sale to the PLCMC. A second online fundraising tactic is the Online Gift Shop. This can be accessed on the "Support the Library" Web page. This page offers online purchase via credit card of PLCMC items, such as shirts, mugs, and books published by the PLCMC. Finally, on the home page, there is a link to subscribe to @TheLibrary newsletter. This email newsletter highlights events, program offerings, and news concerning the PLCMC.

\section{Rowan County Public Library (RPL)}

http://www.lib.co.rowan.nc.us/

While Rowan County's experiment with cyber-fundraising is not as extensive as PLCMC's, it is a good example of how an online presence can work in conjunction with traditional methods of fundraising. The RPL has put an electronic version of its newsletter on the Web. In that newsletter is a section which highlights donations to the RPL foundation, memorials and honorariums, and donations to existing endowments. The site also offers information on how prospective supporters can join the Friends group and a printable membership application is supplied.

\section{Durham County Library}

http://www.durhamcountylibrary.org/

The Durham County Library has a Friends group that dates back 30 years. It has supported the library through volunteer and financial assistance for programs, materials, and equipment. The Friends' site has a link from the library home page. While this page lacks flashy Webtronics, it is a very good source of information concerning ongoing Friends' program and current library funds. It also offers a printable membership form that can be mailed in to join the local chapter.

\section{Union County Public Library}

http://www.union.lib.nc.us/

The Union County Public Library's Web site has a link for Library Support Groups on the home page. In that section there are links highlighting the Union County Library Foundation and the Friends of the Library, including a vast amount of information given to define the mission of each organization. The Foundation's page provides a printable pledge form to make donations to the foundation, while the Friends' page offers a downloadable membership form. This site demonstrates that you do not have to have the latest Web bells and whistles to use cyber-fundraising effectively.

\section{Directions in North Carolina}

Four libraries stated that they were utilizing various methods of cyber-fundraising, but due to the small sample, no concrete conclusions could be drawn. Even so, there are two interesting pieces of data that might indicate the directions in which North Carolina libraries are moving. Of the four libraries that responded positively to the survey, all four were using their Web sites as focal points for their Internet fundraising efforts. Also, three of the four offered on their Web sites some method of making online donations or pledges. These methods ranged from online transactions to printable pledge forms.

The effectiveness of these efforts has not yet been determined. Most of the respondents did not report on the success of their online efforts, but those libraries currently utilizing cyberfundraising did report having done so for a year or less - too short of a time to gauge the true effectiveness of a campaign. While Hickory Public Library's Web site has brought in no direct funds, Director Corki Miller believes that there is a more important intrinsic value to online fundraising: "We know the information is reaching more members of the community - getting the information out is more valuable."

\section{Virtual Friends}

In so far as "getting the information out" is a major theme for the sites above, what better group to accomplish that goal than the Friends of the Library? Friends groups have been the foundation of most library development programs for a long time and it 
only makes sense that these groups become "wired" as well. With the increased technological infrastructure of most public libraries, collaboration between the library's technical staff and the local Friends group could prove to be a fruitful alliance.

Corson-Finnerty and Blanchard believe that for a Friends Web site to be effective it needs to perform three functions. ${ }^{13}$ First, it should keep members informed of news, programs, and events, especially during times of budgetary cuts, when librarians need to be able to mobilize supporters at the last minute. An online newsletter or listserv could be a great tool to send out alerts to gather fast support for a growing issue or decision.

Second, it should provide recognition for the contributions of its members. Naming a building after a benefactor or putting a name in the front of a book are forms of traditional plaquing. Cyberplaquing is providing that recognition in an online environment. ${ }^{14}$ For example, a Web page dedicated to a donor with a history or biography of the person is one way of cyberplaquing.

Finally, the site should provide a way to solicit new members. Increasing membership not only means more revenue from dues, but also an expanded donation network. However, the interactivity of a membership page varies greatly. Union County Public Library includes printable membership forms that can be mailed. Other libraries permit supporters to apply online and pay their membership dues with a credit card.

\section{Where to Start?}

How do we begin to utilize online fundraising techniques in North Carolina public libraries? Carolyn Fox identifies four steps to incorporating the Internet into a development program. ${ }^{15}$ Understanding the limitations and possibilities of technology is the first step. While libraries are aware that they need to incorporate technology into their organizations, they often do not recognize what effect this may have on the library as a whole.

The second step is to understand the Internet itself. The Internet is unlike any technology to come before it. It has transformed our understanding of community by creating its own culture and language. People approach and interact with each other very differently on the Internet than in traditional settings. A set of unwritten rules called "netiquette," which governs interaction on the Internet,

An Internet fundraising strategy needs a vision, goals, and objectives. A fly-by-night idea without guidance can do more damage than not doing anything at all. has emerged. Understanding netiquette is the key to approaching donors and supporters online.

The third step is to determine what Internet tools will be most useful to your library as it devises a fundraising strategy. Again, online fundraising is not for everyone and should not be used just because you can. PLAN, PLAN, and then PLAN again. An Internet fundraising strategy needs a vision, goals, and objectives. A fly-by-night idea without guidance can do more damage than not doing anything at all. For example, a library might set up a Web page that allows supporters to subscribe to an electronic newsletter about the library. This could turn out to be more popular than anticipated, and the number of subscribers could overwhelm existing staff, leading to unanswered e-mails, undelivered issues of the newsletter, and disappointed potential supporters.

Finally, the last step is to incorporate the new tools and strategy into the existing development program. Always remember that cyberfundraising is just a tool to enhance current fundraising efforts. Don't abandon face-to-face contact; use the Internet to initiate that contact. 
Incorporating one technology at a time and piloting new techniques with established supporters before full implementation will save valuable resources and ensure a successful project.

\section{Measuring Success}

Measuring success can be somewhat cumbersome, but it is very important in determining the strategies to incorporate into a long-term development plan. According to Michael Stein, there are three ways to measure your success. ${ }^{16}$ One is to assess whether you are actually building an audience for your efforts. Track hits to your Web sites or listservs, but realize that you must be in this for the long haul. It could possibly take two or more years before you see any success.

The second is in the feedback you get from your supporters. Gather this feedback in any way possible - through surveys, e-mail, focus groups, etc. This could be your best measure, since you're utilizing this technology to make things easier for the patron. Remember, technology does not always save staff time and sometimes it may increase the workload. Staff time versus fundraising success is often a positive relationship. The more time you can devote to this effort, the more successful your results. The ultimate goal of

Track hits to your Web sites or listservs, but realize that you must be in this for the long haul. It could possibly take two or more years before you see any success. making things easier for the patron/supporter should never be lost in the implementation of any new technology. While your older patrons may have an aversion to these new fundraising methods, there is a larger, younger population that needs to be tapped for future support. A good balance of traditional and online fundraising methods eliminates the possibility of alienating supporters.

The third way to measure success is whether or not you're raising money from this effort. Ask people why they gave the money. If you are taking money through electronic transactions such as credit cards, these transactions should be easy to trace. However, if you have a printable membership form that people mail in with dues, this may be a little harder. A cost-benefit analysis might be a good method to determine how much it is costing you to raise funds. Don't forget that when managed effectively, online fundraising can save you money - and saving money is the same as raising it.

\section{Push or Pull?}

In order to make money, people must know how to promote these resources. The maxim "build it and they will come," doesn't work as well on the Internet as it does in the movies. There are two strategies for drawing people to your site-pull and push. "A pull strategy draws your prospect to your site," while a push strategy "takes your message or site to the prospect." 17

For online fundraising, a pull strategy tends to be much more effective and library sites already have an innate pull due to their content. In contrast, a push strategy can be seen exactly as that - "pushy." This type of strategy is what most Internet users call spam. Instead of spamming someone with unrequested e-mail, you could place a button on your Web site for requesting a newsletter or listserv. In this way, the prospect has consented to be solicited concerning library support.

\section{Conclusion}

While many tools are available to fundraisers interested in online fundraising, cyber-fundraising seems to lend itself to some common guidelines: 
- If you build it, they won't just come.

You have to promote your new online fundraising efforts.

- Be able to understand technology and have a vision.

Your library's online efforts are a marketing and fundraising tool. You must be able to understand technology, what it can and cannot do for you. You must have a vision for your cyber-fundraising efforts.

- It's all about your supporters. Know your donors and supporters. Make online giving easy and give your donors options.

- Cyber-fundraising enhances traditional fundraising efforts. Your cyber-fundraising projects are nothing alone. You must incorporate it into the mission of the library and its overall development plan.

- Ethics, privacy and security are still important.

As with patron information, the privacy of donor's/supporter's information should be considered off-limits except for library purposes.

- Cyber-fundraising is not the magic bean. Cyber-fundraising is a tool to be used in your fund raising strategy. It SHOULD NOT be viewed as a quick cure.

- Success online means obeying "netiquette." You must target your audience and drive their attention to the wealth of information and services offered by your online presence. Permission must be sought before you begin direct communication via the Internet.

- Cyber-fundraising is about relationship building.

The Internet offers the opportunity to effectively build a community of supporters. Don't abandon face-to-face contact; use the Internet to initiate that contact. ${ }^{18}$

Considering the recent cutbacks and legislative cold shoulder to the library's role in society, it is not surprising that skepticism exists concerning cyber-fundraising. After all, if a library has the choice between starting such a program, and offering basic services, most of us would vote for the basics. However, as we have seen, a well-organized online fundraising effort can be a valuable addition to any library development program and as the cost of getting online continues to decrease, even the smallest library can take advantage of online fundraising techniques.

While it appears that cyber-fundraising in North Carolina is in its infancy, the examples in this article illustrate the pioneering trends of several libraries. Their exploration into this new medium represents the beginning of a new era in library development. With the Internet emerging as a preferred method of communication and public funding decreasing, the very future of the public library may depend upon how effectively we are at attracting new generations of supporters.

\section{References}

1 Mark Johnson, "State's Budget Comes Up Short Almost \$1 Billion," Charlotte Observer, 6 Mar. 2002, available from http://www.ncdot.org/ news/dailyclips/2002/02 02/2002-02-06aa.html, Internet, accessed 10 Oct. 2002.

2 Geoff Cantrell, "State Budget Cuts Harm Region's Smaller Libraries," Asheville Citizen-Times, 8 May 2002, available from http://cgi.citizen- 
times.com/cgi-bin/story/news/12513, Internet, accessed 8 Oct. 2002.

3 Evan St. Lifer, "Libraries Succeed at Funding Books and Bytes," Library Journal 124 (Jan. 1999): 51.

4 Adam Corson-Finnerty and Laura Blanchard, Fundraising and FriendRaising on the Web (Chicago:American Library Association, 1998), 5-6.

5 Swapan Garain, "Cyber Fundraising," Humanscape 7 (June 2002), available from http://www.humanscapeindia.net/humanscape/hs0600/ hs60010t.htm, Internet, accessed 15 Oct. 2002.

6 Ibid.

7 Corson-Finnerty and Blanchard, 4-5.

8 Mellman Group, Social Engaged Internet Users: Prospects for Online Philanthropy and Activism (Arlington: CMS Interactive, 1999), 4.

9 Ibid., 7.

10 Ibid., 8 .

11 Corson-Finnerty and Blanchard, 3-4.

12 Directory of North Carolina Public Libraries: July 1, 1999-June 30, 2000, available from http://statelibrary.dcr.state.nc.us/ld/99 2000directory.pdf, Internet, accessed 10 Oct. 2002.

13 Corson-Finnerty and Blanchard, 44.

14 David King, "Soliciting Virtual Money," Library Journal, Net Connect Supplement 125 (Oct. 2000): 40.

15 Cheryl Fox, Fundraising and the Internet: Making It a Part of a Successful Development Program (M.A. thesis, St. Mary's University of Minnesota, 1997), 11-13.

16 Michael Stein, "Tools You Can Use Online," in Fundraising on the Internet: Recruiting and Renewing Donors Online, ed. Nick Allen, Mal Warwick, and Michael Stein (Berkeley: Stratmorr Press, 1996), 3, 11. 17 Adam Corson-Finnerty, "Cybergifts," Library Trends 48 (Winter 2000): 624.

18 The Ten Rules of e-Philanthrophy That Every Nonprofit Must Know, available from http://www.ephilanthropyfoundation.homestead.com/ tenrules.html, Internet, accessed 15 Oct. 2002. 